\title{
INEQUALITIES IN CANCER DEATHS BY AGE, GENDER AND EDUCATION
}

\author{
Marek Gróf', Tatiana Vagašová', Marián Oltman², L'ubomír Skladaný3, Lenka Maličká1 \\ ${ }^{1}$ Faculty of Economics, Technical University of Košice, Košice, Slovak Republic \\ ${ }^{2}$ Center for Gastroenterology and Hepatology Thalion, Bratislava, Slovak Republic \\ ${ }^{3}$ Department Internal Medicine II, Faculty of Medicine, Slovak Medical University in Bratislava, F. D. Roosevelt University Hospital, Banská \\ Bystrica, Slovak Republic
}

\section{SUMMARY}

Aim: The economy of each state provides a significant amount of money into the health care system with the aim of knowing the health status of its population in the context of socioeconomic characteristics for effective resource allocation. In recent years, there is a growing number of cancer deaths in Slovakia. Therefore, the structure of cancer deaths according to its primary determinants, such as age, sex and education with the aim of effective implementation of prevention programs in Slovakia was examined.

Methods: Main source of data on deaths from 1996 to 2014 was provided by National Health Information Centre in Slovakia. However, data were available only from 2011. Standardized mortality rate per 100,000 inhabitants was estimated by the method of direct standardization using European standard population. The $\mathrm{R}$ project for statistical computing was used for calculation of statistically significant differences among various groups of mortality.

Results: The results show that people with primary education die from cancer later than people with higher education. However, major differences related to both sex and age are present in people with university education. A different variety of cancers occur in childhood (neoplasm of brain), adolescents (neoplasm of bone), young adults (neoplasm of brain), or adults (lung cancer and breast cancer). Malignant neoplasm of brain was more prevalent at higher education levels, Malignant neoplasm of bladder and Malignant melanoma of skin were more prevalent at the university level of education.

Conclusions: The results can be useful for economists to define the health priorities in each country, make the financial decisions in economics, and thus contribute to better health, economic growth, as well as effective spending of health expenditures.

Key words: standardized mortality rate, cancer, education, health policy

Address for correspondence: M. Oltman, Center for Gastroenterology and Hepatology Thalion, Tomášikova 50/C, 83104 Bratislava, Slovak Republic. E-mail: oltman@thalion.sk

https://doi.org/10.21101/cejph.a5055

\section{INTRODUCTION}

Cancer is a global problem and remains a challenge mainly in low and middle income countries, where access to treatment is limited for people with lower socioeconomic status. Education has been one of the most important social determinants of health. It can be assumed that the decline of investment in education results in the pressure for an increase in the costs of medical services. The more students continue their education at secondary level, the higher chances of a healthy population occur (1).

Generally, many studies have provided the evidence that the educational attainment strongly and negatively correlates, not only with the all-cause mortality (2-5), but also with cancer mortality (6-12). Moreover, Rogers et al. (13) demonstrate that education has a stronger impact on mortality than income of population. Albano et al. (9) showed that black men with completed twelve or more years of education had more than twice higher prostate cancer death rate compared to black men who were more educated in the USA. In addition, breast cancer death rates were higher among women with lower education than among women with higher education. At the level of Barcelona city, Fernandez and Borrell (11) demonstrated the negative association between educational level and mortality from cancer mainly due to larynx among men and cervical cancer among women. Surprisingly, positive relationships were found for cancer of pancreas, lung and breast for women with secondary level of education. Previous studies have shown that there are inequalities in cancer mortality and their sizes differ according to socioeconomic characteristics of individuals.

The main goal of this paper is to reveal trends of cancer mortality in Slovakia and identify differences for different sex, age and education level groups as well as leading causes of cancer deaths for these groups for the 1996-2014 time period.

\section{MATERIALS AND METHODS}

Main source of data on deaths by age, sex, and cause of death from 1996 to 2014 was provided by National Health Information Centre in Slovakia. Data of education included in death certificates was available only from 2011 onwards. 
Standardized mortality rate per 100,000 inhabitants was estimated by the method of direct standardization using European standard population. Age groups were selected using the Provisional Guidelines on Standard International Age Classifications by the United Nations.

The raw data was processed by using the $\mathrm{R}$ project for statistical computing. Either the Mann-Whitney U test or Kruskal-Wallis test were performed in order to identify statistically significant differences among various groups of mortality.

\section{RESULTS}

\section{Development of Mortality by Sex, Age and Leading Causes of Deaths Structure}

The standardized mortality rates of cancer changed very slightly between the years 1996 and 2014 (Fig. 1). A little drop from 492 per 100,000 of inhabitants in 1996 to 455 per 100,000 inhabitants in $2014(-7.6 \%)$ was recorded for men compared to the increase by $2.1 \%$ for women, from 228 per 100,000 inhabitants to 232 per 100,000 inhabitants. Mortality rates for men are approximately twice higher than those for women.

Table 1 reports the descriptive statistics of age structure in mortality for cancer, separately for men and women. The share on all-cause mortality is an average of $23 \%$ and $25 \%$ proportion for men and $20 \%$ for women. The median age is set at 67 years for men and 70 years for women. An inter-quartile range expresses the variability of age structure pertaining to the statistical dataset. The lower variability is revealed in men considering a narrower range between 25 th and 75 th percentile.

It can be expected that different age composition of the population will relate to the various types of cancer deaths. Figure 2 shows that the leading cause of cancer deaths is the malignant

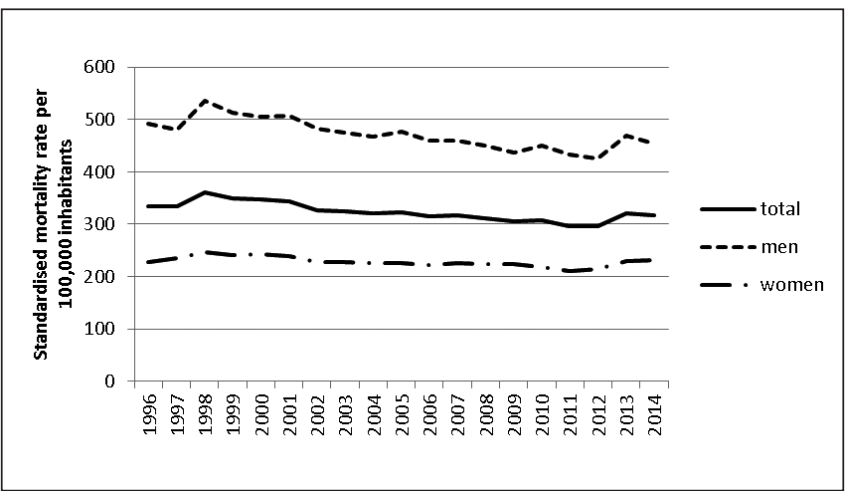

Fig. 1. Development of mortality from cancer by sex, 19962014. neoplasm of brain (C71) for children (under 15 year), similarly for young adults (19-30 age cohort). On the other hand, adolescents (15-18 age cohort) died from malignant neoplasm of bone and articular cartilage of limbs (C40) almost in the same share as from C71. People with age above 31 years differ from younger age cohorts. The difference lies in the types of cancer deaths among specific age cohorts. During the explored period, people at the age cohort of 31-45 were especially burdened by lung cancer (C34) and breast cancer (C50). The 46-62 age cohort is mainly characterized by deaths from lung cancer (C34) and breast cancer (C50). At ages 63 and over, the top diagnosis is the same as previous, but the second most common type was mortality from malignant neoplasm of colon (C18). The lower diversity of cancer deaths is observed under age of 18. A stable increase can be observed at the 46-62 and 63-103 age cohorts. On the contrary, a dramatic decrease was recorded for people aged 31-45 and partially for 19-30 that suggests an improvement of some factors that affect cancer mortality.

\section{Education, Age, Sex and Mortality}

The age distribution by level of education of the Slovak population seems to be similar for incomplete secondary, secondary and university level, except the primary education (Table 2, Fig. $3)$. The proportion of the population with primary education accounts for $18 \%$ representing the lowest value of the educational attainment levels during the period of 2011-2014. On the other hand, people with primary education died later, since the median age is set at 75 years and 65 years in 25 th percentile of age. The third quartile demonstrates that the quarter of primary educated

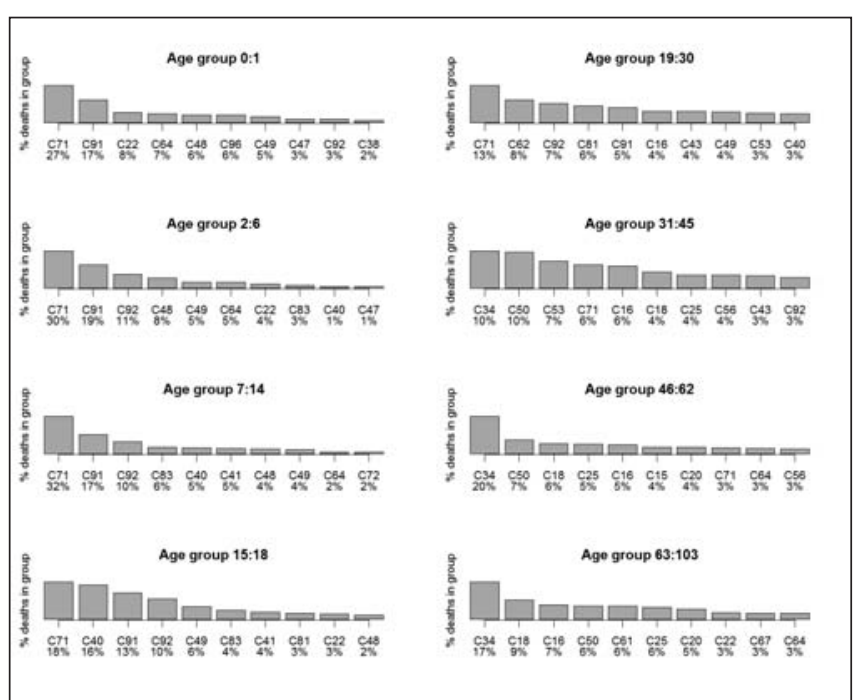

Fig. 2. The leading causes of cancer deaths at different age cohorts.

Table 1. Cancer deaths by gender distribution from 1996 to 2014

\begin{tabular}{|l|c|c|c|c|c|c|}
\hline & Counts of deaths & $\begin{array}{c}\text { Annual average } \\
\text { deaths }\end{array}$ & \% of total mortality & Median age & $\begin{array}{c}\text { 25th percentile of } \\
\text { age }\end{array}$ & $\begin{array}{c}\text { 75th percentile of } \\
\text { age }\end{array}$ \\
\hline Total & 226,134 & $11,901.79$ & $22.7 \%$ & 68 & 59 & 77 \\
\hline Men & 132,029 & $6,948.895$ & $25.1 \%$ & 67 & 58 & 75 \\
\hline Women & 94,105 & $4,952.895$ & $19.9 \%$ & 70 & 60 & 79 \\
\hline
\end{tabular}


people died at the age of 82 and over. Other educational levels gained values in average of $30 \%$ share of all-cause mortality in a given educational group. However, the inter-quartile range is the narrowest in the case of incomplete secondary education, while the highest variability of age is referred to people with university education.

It was tested whether the age distributions of mortality in the specific educational levels are from the same basic population. Based on the Kruskal-Wallis chi-squared test (test statistics: 3224.858; p-value <0.001) it was found out that at least one pair is different. To identify a concrete pair, post hoc test is used. It was explored that all pairs among educational levels are different and significant (Table 3).

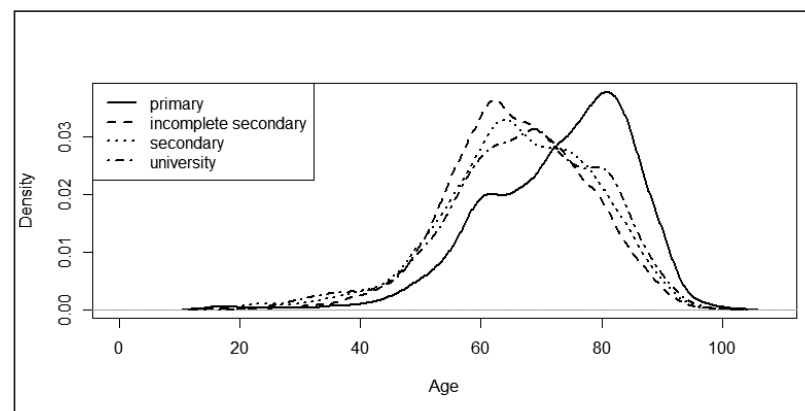

Fig. 3. Age distribution of cancer related deaths for different education levels for 2011-2014.
Mortality of the population with primary or incomplete secondary education was higher for men in comparison to women (Table 4). According to the median or inter-quartile range, women die later than men, but variability is higher for men with primary education and for women with incomplete secondary education. Opposite results were found for the two remaining educational levels. Women die later than men, and variability of age distribution by education was higher for women with secondary education and for men with university education. Major differences related to both sex and age are characteristic for people with university education. Median age is higher by 8 years for men. Similarly, the 25 th and 75 th percentiles are significantly higher for men.

The occurrence of differences between men and women by education was examined by using MW test, with statistically significant differences between sex groups at all education levels.

Figure 4 shows that substantial differences of genders are observed at the primary and incomplete educational level. The most numerous deaths are around 80 years for both sexes with the primary education and around 60 years in both secondary levels. Men with the university education die mostly at the age of 70 compared to the age of 60 for women.

Further attention was paid to identifying differences in prevalence of individual diagnoses among groups with different attained education. Table 6 presents the top 15 cancer diagnoses and the $\%$ of deaths (among all cancer related deaths) attributed to them. For most diagnoses, the differences are insignificant with three notable exceptions. The first is the diagnosis C71 - Malignant neoplasm of brain with prevalence increasing from $2.08 \%$ and $2.69 \%$ for primary and incomplete secondary education respectively to

Table 2. Age structure of deaths due to cancer in relation to educational level

\begin{tabular}{|l|c|c|c|c|}
\hline & \% of total mortality & Median age & 25th percentile of age & 75th percentile of age \\
\hline Primary & 18.3 & 75 & 65 & 82 \\
\hline Incomplete Secondary & 29.5 & 66 & 59 & 74 \\
\hline Secondary & 31.8 & 67 & 59 & 76 \\
\hline University & 32.7 & 68 & 59 & 77 \\
\hline
\end{tabular}

Table 3. Results of post hoc test ( $p$-value)

\begin{tabular}{|l|c|c|c|}
\hline & Primary & Incomplete secondary & Secondary \\
\hline Incomplete secondary & $<0.001$ & & \\
\hline Secondary & $<0.001$ & $<0.001$ & $<0.001$ \\
\hline University & $<0.001$ & $<00387$ \\
\hline
\end{tabular}

Table 4. Age structure by gender of deaths due to cancer in relation to educational level

\begin{tabular}{|l|c|c|c|c|c|c|c|c|}
\hline & $\begin{array}{c}\text { \% of total } \\
\text { deaths men }\end{array}$ & $\begin{array}{c}\text { \% of } \\
\text { total deaths } \\
\text { women }\end{array}$ & $\begin{array}{c}\text { Median age } \\
\text { men }\end{array}$ & $\begin{array}{c}\text { Median age } \\
\text { women }\end{array}$ & $\begin{array}{c}\text { 25th percen- } \\
\text { tile men }\end{array}$ & $\begin{array}{c}\text { 25th percen- } \\
\text { tile women }\end{array}$ & $\begin{array}{c}\text { 75th percen- } \\
\text { tile men }\end{array}$ & $\begin{array}{c}\text { 75th percen- } \\
\text { tile women }\end{array}$ \\
\hline Primary & 23.3 & 15.5 & 72 & 77 & 62 & 69 & 80 & 83 \\
\hline $\begin{array}{l}\text { Incomplete } \\
\text { secondary }\end{array}$ & 30.1 & 28.1 & 65 & 67 & 59 & 59 & 73 & 76 \\
\hline Secondary & 30.4 & 33.6 & 67 & 66 & 60 & 58 & 76 & 75 \\
\hline University & 29.5 & 41.6 & 71 & 63 & 62 & 55 & 79 & 71 \\
\hline
\end{tabular}



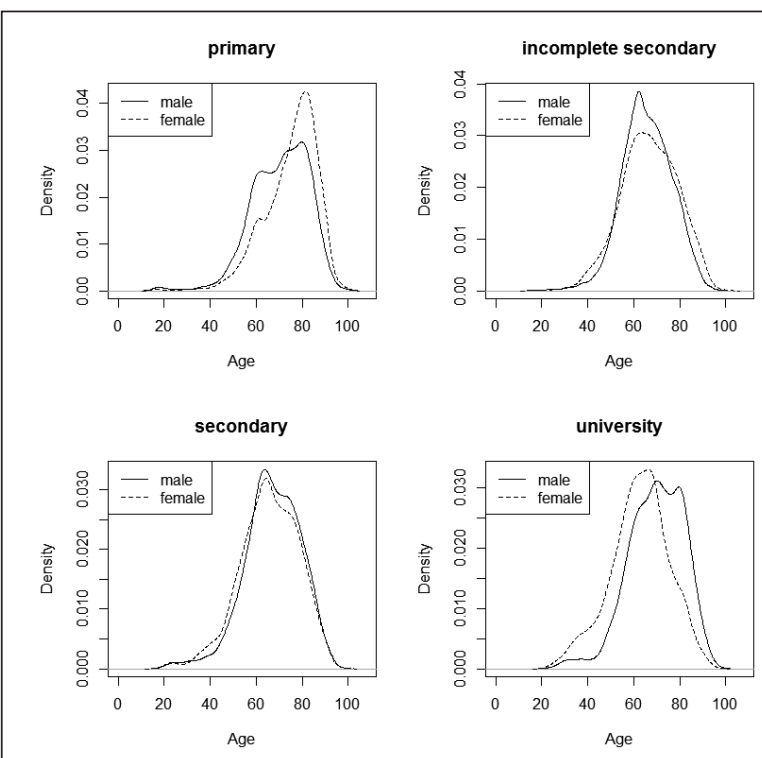

Fig. 4. Differences in age distribution for different sex and education levels for cancer related deaths for 2011-2014.

$3.61 \%$ and $3.99 \%$ for secondary and university education. This difference is statistically significant (Pearson's chi-squared test, p-value $<0.001$ ), unaffected by sex. This result is consistent with the results reported by Khanolkar et al. (14). The second exception is the diagnosis C67-Malignant neoplasm of bladder. In this case, the prevalence is around $2.5 \%$ for the primary, incomplete secondary and secondary education levels, irrespective of sex, but records 3.5\% prevalence in university educated subjects, testing positively for statistical significance (Pearson's chi-squared test, $\mathrm{p}$-value $<0.001$ ). The final exception is the diagnosis C43 - Malignant melanoma of skin. In this particular case, the prevalence of the primary, incomplete secondary and secondary education levels is relatively even at around $1.5 \%$. However, for the university educated group, the prevalence as the cause of death among all the cancer related diagnoses is doubled $3.07 \%$, testing statistically significant (Pearson's chi-squared test, $p$-value $<0.001$ ). Specific reasons for these differences are subject to further planned study.

\section{DISCUSSION}

It was found out that the development of the standardized mortality rates of cancer was relatively stable in the long term, although, it has steadily increased in 2012 what may indicate a rising burden of cancer diseases at present. Men demonstrated twice higher mortality rates than women, however, trend is slightly decreasing among men compared to the increased number of women. Lower variability was also revealed in men.

During 1996-2014, the median age for men was 67 years compared to 70.5 years of life expectancy at birth. Women outlived men by about 8 years on 78.1 years and the median age was 70 years. The difference between median age and life expectancy at birth is narrower for males than for females. This demonstrates that women are exposed to higher risk of premature deaths compared to men.

A different variety of cancers occur in childhood, young adults or adults. People under 30 years die predominantly of brain and bone cancers, potentially resulting from genetic susceptibility to cancer (15). On the contrary, lung, breast or colon cancers burdening Slovak adults the most are the results of an unhealthy lifestyle, high consumption of alcohol or cigarettes.

For the period of 1996-2014, significant decreases of all cancers were observed at the age cohorts of 19-45 suggesting more effective introduction of the prevention programs rather than in older people.

It was also proved that the most significant change in cancer mortality by educational level was found between primary and incomplete secondary education. People with primary education die at about 80 years old. The potential explanation can be that

Table 5.Top causes of death for different education levels

\begin{tabular}{|l|c|c|c|c|c|c|c|}
\hline \multicolumn{2}{|c|}{ Primary } & \multicolumn{2}{c|}{ Incomplete secondary } & \multicolumn{2}{c|}{ Secondary } & \multicolumn{2}{c|}{ University } \\
\hline Diag & \% of deaths & Diag & \% of deaths & Diag & \% of deaths & Diag & \% of deaths \\
\hline C34 & 16.97 & C34 & 18.74 & C34 & 14.65 & C34 & 13.11 \\
\hline C18 & 8.82 & C18 & 7.89 & C18 & 8.66 & C18 & 9.25 \\
\hline C50 & 7.82 & C25 & 5.46 & C50 & 8.59 & C61 & 8.57 \\
\hline C25 & 5.47 & C16 & 5.32 & C25 & 6.46 & C50 & 7.67 \\
\hline C16 & 5.42 & C20 & 4.77 & C16 & 4.80 & C25 & 6.32 \\
\hline C20 & 4.60 & C61 & 4.73 & C61 & 4.64 & C16 & 5.24 \\
\hline C61 & 4.35 & C50 & 4.69 & C20 & 4.45 & C71 & 3.99 \\
\hline C22 & 3.01 & C64 & 3.27 & C71 & 3.61 & C20 & 3.97 \\
\hline C64 & 3.01 & C22 & 3.14 & C64 & 3.10 & C67 & 3.57 \\
\hline C80 & 2.83 & C15 & 3.05 & C22 & 3.01 & C43 & 3.07 \\
\hline C67 & 2.59 & C71 & 2.69 & C56 & 2.93 & C22 & 2.72 \\
\hline C56 & 2.30 & C80 & 2.67 & C67 & 2.55 & C64 & 2.67 \\
\hline C54 & 2.28 & C67 & 2.42 & C53 & 2.36 & C19 & 2.49 \\
\hline C71 & 2.08 & C19 & 2.01 & C80 & 2.16 & C56 & 1.98 \\
\hline
\end{tabular}


most of them did not have the possibility of higher education around 80 years ago. Equally, the highest variability of age was recorded for the people with university education.

Mortality of the population with both primary and incomplete secondary education was higher for men compared to women. These men are usually occupied as workers who are often exposed to environmental risks. Thus, they are characterized by higher level of cancer mortality.

Major differences related to both sex and age are characterized by people with university education. Median of age is higher of 8 years for men. However, the lower number of male mortality from cancer can indicate that larger amount of men could die from other diseases at younger age. Therefore, cancer disease presence is lower for university educated men than for women.

Statistically significant differences were detected in the case of diagnoses C71, C67 and C43, where these diagnoses presented a more prevalent cause of death within the higher educated groups.

\section{CONCLUSIONS}

Education is a useful determinant of cancer deaths identifying risk groups in devising effective health interventions. For cancer control, it is necessary to gather incidence and mortality accurate data and assess cancer disparities by socioeconomic status. People with low educational level usually have financial problems, poor housing conditions, and unsafe environments, all contributing to an unhealthy situation and leading to premature deaths (16-20).

While a different variety of cancers occur in childhood (neoplasm of brain), adolescents (neoplasm of bone), young adults (neoplasm of brain), or adults (lung cancer and breast cancer), tracking cancer mortality by education provides information about effectiveness of the previous prevention programs in each country, and helps health policy makers in making decisions. This leads to devising programs for specific groups of people rather than for the total population. People with primary education level died at higher ages on average than people with incomplete or complete secondary education. At the university education level, a difference between men and women was present, with women succumbing to cancer related diseases at a lower age than men. Malignant neoplasm of brain was more prevalent at higher education levels, Malignant neoplasm of bladder and Malignant melanoma of skin were more prevalent at the university level of education.

\section{Acknowledgements}

This work was supported by the VEGA project No. 1/0945/17 Economic research on quantification of marketing processes aimed at improving value for patient, multidimensional analyses of the marketing mix of healthcare facilities and quantification of their importance in the process of establishment of the system to measure the quality and efficiency in healthcare of the Slovak Republic.

\section{Conflict of Interests}

None declared.

\section{REFERENCES}

1. Pol L, Thomas R. The Demography of health and healthcare. Dordrecht: Springer; 2013.

2. Kibele EUB. Regional mortality differences in Germany. Dordrecht: Springer; 2012.

3. Hoffmann R. Socioeconomic differences in old age mortality. Dordrecht: Springer; 2008.

4. Muller A. Education, income, inequality, and mortality: a multiple regression analysis. BMJ. 2002 Jan 5;324(7328):23-5.

5. Kunst AE, Mackenbach JP. The size of mortality differences associated with the educational level in nine industrialized countries. Am J Public Health. 1994;84(6):932-7.

6. Vanthomme K, Vandenheede H, Hagedoorn P, Gadeyne S. Socioeconomic disparities in lung cancer mortality in Belgian men and women (20012011): does it matter who you live with? BMC Public Health. 2016 Jun 10;16:493. doi: 10.1186/s12889-016-3139-1.

7. Koch E, Romero T, Romero CX, Akel C, Manríquez L, Paredes M, et al. Impact of education, income and chronic disease risk factors on mortality of adults: does 'a pauper-rich paradox' exist in Latin American societies? Public Health. 2010;124(1):39-48.

8. Mackenbach JP, Stirbu I, Roskam AR, Schaap MM, Menvielle G, Leinsalu $\mathrm{M}$, et al. Socioeconomic inequalities in health in 22 European countries. N Engl J Med. 2008;358(23):2468-81.

9. Albano JD, Ward E, Jemal A, Anderson R, Cokkinides VE, Murray T, et al. Cancer mortality in the United States by education level and race. J Natl Cancer Inst. 2007;99(18):1384-94.

10. Kalediene R, Petrauskiene J. Inequalities in mortality by education and socio-economic transition in Lithuania: equal opportunities? Public Health. 2005;119(9):808-15.

11. Fernandez E, Borrell C. Cancer mortality by educational level in the city of Barcelona. Br J Cancer. 1999;79(3-4):684-9.

12. Faggiano F, Lemma P, Costa G, Gnavi R, Pagnanelli F. Cancer mortality by educational level in Italy. Cancer Causes Control. 1995;6(4):311-20.

13. Rogers RG, Hummer RA, Nam CB. Living and dying in the USA: behavioral, health, and social differentials of adult mortality. San Diego: Academic Press; 2000.

14. Khanolkar AR, Ljung R, Talbäck M, Brooke HL, Carlsson S, Mathiesen $\mathrm{T}$, et al. Socioeconomic position and the risk of brain tumour: a Swedish national population-based cohort study. J Epidemiol Community Health. 2016 Dec;70(12):1222-8.

15. Stewart BW, Wild CP. World cancer report 2014. Lyon: WHO; 2014.

16. Šoltés V, Gavurová B. The possibilities of day surgery system development within the health policy in Slovakia. Health Econ Rev. 2014;4:35. doi:10.1186/s13561-014-0035-1.

17. Gavurova B, Soltes M. System of day surgery in Slovakia: analysis of pediatric day surgery discrepancies in the regions and their importance in strategy of its development. E M Ekon Manag. 2016;19(1):74-92.

18. Gavurová B, Vagašová T. Regional differences of standardised mortality rates for ischemic heart diseases in the Slovak Republic for the period 1996-2013 in the context of income inequality. Health Econ Rev. 2016;6:21. doi:10.1186/s13561-016-0099-1.

19. Šoltés V, Gavurová B. The Functionality comparison of the health care systems by the analytical hierarchy process method. E M Ekon Manag. 2014;17(3):100-17.

20. Soltes, M., Gavurova, B. Quantification and comparison of avoidable mortality - causal relations and modification of concepts. Technol Econ Dev Econ. 2015; 21(6):917-938. 